\title{
Impacts of mycobacteriosis on the growth of striped bass (Morone saxatilis) in Chesapeake Bay
}

\author{
Robert J. Latour, David T. Gauthier, James Gartland, Christopher F. Bonzek, \\ Kathleen A. McNamee, and Wolfgang K. Vogelbein
}

\begin{abstract}
The striped bass (Morone saxatilis) is an economically and ecologically valuable finfish species that inhabits nearshore and estuarine waters of many states along the US Atlantic coast. Chesapeake Bay provides extensive nursery and foraging habitats for striped bass, yet fish in the bay exhibit high prevalence of disease caused by bacteria in the genus $M y$ cobacterium. Detection of population-level impacts associated with mycobacteriosis has been difficult because the disease is chronic and synoptic biological and disease data have been limited. Here, we present modeling analyses of growth data for disease-positive and -negative striped bass in Chesapeake Bay. Three growth relationships were considered, and for each, a single model was parameterized to include several covariates, most notably disease status and severity. Our results indicate that disease-positive and -negative fish have differing growth patterns and that the estimated asymptotic sizes of diseasepositive fish are considerably lower than those of disease-negative fish. Compromised growth along with documentation that striped bass in Chesapeake Bay are experiencing disease-associated mortality suggests that disease may be reducing the productivity of this species.
\end{abstract}

Résumé : Le bar rayé (Morone saxatilis) est un poisson téléostéen de grande importance économique et écologique qui habite les eaux côtières et estuariennes de plusieurs états de la côte atlantique des É.-U. La baie de Chesapeake fournit d'importants habitats de nourricerie et d'alimentation au bar rayé, bien que les bars dans la baie connaissent une forte prévalence de maladie causée par des bactéries du genre Mycobacterium. La détection des impacts de la mycobactériose au niveau de la population est difficile, car la maladie est chronique et il existe peu de données synoptiques sur la biologie et la maladie. Nous fournissons ici des données de croissance dans la baie de Chesapeake chez des bars rayés présentant une réaction positive à la maladie et d'autres une réaction négative. Nous avons tenu compte de trois relations de croissance et, pour chacune, nous avons paramétré un seul modèle de manière à inclure plusieurs covariables, en particulier le statut et la sévérité de la maladie. Les poissons à réaction positive et négative affichent des patrons de croissance différents et les tailles estimées à l'asymptote des poissons à réaction positive sont considérablement inférieures à celles des poissons à réaction négative. La croissance restreinte, ainsi que l'évidence de mortalité associée à la maladie, laissent croire que la maladie est en train de réduire la productivité du bar rayé dans la baie de Chesapeake.

[Traduit par la Rédaction]

\section{Introduction}

Fish production can be defined as the time- and areaspecific elaboration of tissue balanced with losses due to natural and fishing mortality (Clarke 1946; Mertz and Myers 1998). Growth rates of fishes are known to vary with a wide array of physical, biological, and ecological variables such that they may be viewed as species-specific responses to particular conditions within an ecosystem (Beck et al. 2001). Favorable ecosystem conditions will allow fish to achieve maximum growth potential, which confers increased survival (Houde 1987) and reproductive potential (Zastrow et al. 1989). On the other hand, poor ecosystem conditions will have the opposite effect and lead to compromised growth potential. Fish growth can therefore be used as an indicator of habitat quality and ecosystem health, as it integrates both natural and anthropogenic causes of ecosystem change (Brandt and Kirsch 1993; Greenstreet and Rogers 2006).

Chesapeake Bay is the largest estuarine ecosystem in North America and provides critical foraging and refuge habitat for many mid-Atlantic fishes (Murdy et al. 1997). The bay watershed has experienced considerable anthropogenic change over the past century, particularly in the form of habitat loss and eutrophication (Kemp et al. 2005; Diaz and Rosenberg 2008). Several disease outbreaks within fish pop-

Received 28 January 2011. Accepted 19 October 2011. Published at www.nrcresearchpress.com/cjfas on 31 January 2012.

J2011-0012

Paper handled by Associate Editor Deborah MacLatchey.

R.J. Latour, J. Gartland, C.F. Bonzek, K.A. McNamee, and W.K. Vogelbein. Virginia Institute of Marine Science, College of William \& Mary, P.O. Box 1346, Gloucester Point, VA 23062, USA.

D.T. Gauthier. Department of Biological Sciences, 106B Mills Godwin Building, Old Dominion University, Norfolk, VA 23529, USA.

Corresponding author: R.J. Latour (e-mail: latour@vims.edu). 
ulations in the bay have been documented in recent decades, a notable one being mycobacteriosis in striped bass (Morone saxatilis). In 1997, histopathology of splenic tissue from Chesapeake Bay striped bass revealed granulomatous inflammation associated with acid-fast bacteria, consistent with infection by Mycobacterium spp. (Vogelbein et al. 1999; Gauthier and Rhodes 2009). Subsequent surveys of striped bass in the bay have demonstrated high prevalence of both visceral and dermal mycobacteriosis, with the latter exceeding $75 \%$ in some age groups (Vogelbein et al. 1999; Overton et al. 2003; Gauthier et al. 2008).

Mycobacteriosis is a cosmopolitan disease of fishes, affecting a wide range of wild and aquacultured species. The $M y$ cobacterium spp. most commonly associated with infections are $M$. marinum, M. fortuitum, and $M$. chelonae, although the diversity of Mycobacterium spp. shown to infect fishes has steadily increased in recent years (Gauthier and Rhodes 2009). Isolates from Chesapeake Bay striped bass, in particular, present a unique picture of etiology, with the new species Mycobacterium shottsii (Rhodes et al. 2003) and Mycobacterium pseudoshottsii (Rhodes et al. 2005) most commonly recovered, followed by a diverse suite of slow-growing isolates (Rhodes et al. 2004). Mycobacteriosis in striped bass is most commonly manifested as visceral disease, with spleen and anterior kidney as the primary target organs. Dermal disease presentations are also commonly seen, with extensive, shallow ulcerative lesions that may compromise a large portion of the external surface of the affected fish (Gauthier et al. 2008; Gauthier and Rhodes 2009).

Population-level impacts of mycobacteriosis in Chesapeake Bay striped bass have generally been difficult to detect due to the chronic nature of the disease. Jiang et al. (2007) analyzed tag-recovery data from striped bass in Maryland waters and demonstrated that the rate of natural mortality has increased relative to previously assumed levels. Interpretation of this result leads to the hypothesis that mycobacteriosis may be contributing to elevated natural mortality rates in Chesapeake Bay striped bass. To address the mortality hypothesis more directly, Gauthier et al. (2008) used an epidemiological model to analyze prevalence data of striped bass from the bay mainstem (i.e., non-tributary waters) and demonstrated disease-associated mortality. However, questions about other population-level impacts remain, particularly how the disease impacts growth, reproduction, physiology, behavior, and trophic ecology.

In this paper, we evaluate the population-level impacts of mycobacteriosis on the growth of Chesapeake Bay striped bass. Three growth relationships were considered, namely those that describe length-at-age, eviscerated mass-at-length, and eviscerated mass-at-age, and for each relationship, a single growth model was parameterized to include a variety of covariates with the focal variables being disease status and severity. A model selection criterion was used to discriminate among competing models within each analysis and to draw inferences about the potential impacts of disease on growth. Collectively, our results provide insights into the impacts of mycobacteriosis on the growth of striped bass, which when combined with knowledge regarding disease-associated mortality, contribute to our understanding of disease impacts on the productivity of striped bass in Chesapeake Bay.

\section{Materials and methods}

\section{Field collections}

All field methods associated with the capture of striped bass were described previously by Gauthier et al. (2008). In summary, fish were collected by the Chesapeake Bay Multispecies Monitoring and Assessment Program (ChesMMAP), which is a fisheries-independent bottom trawl survey that samples late-juvenile and adult fishes in the bay mainstem. From 2003 to 2007, a total of 24 ChesMMAP cruises were conducted (bimonthly from March to November each year with the exception of September 2007). Approximately 80 sites were sampled during each cruise according to a stratified random sampling design (Fig. 1). A randomly selected subsample of up to five fish per size class if multiple were collected (e.g., small, medium, large) were measured for fork length (FL, mm) and eviscerated and total mass (kg). Additional processing was conducted for macroscopic sex determination, otolith-based aging, and histological detection of splenic mycobacteriosis. All protocols for sampling and euthanizing fish were approved by the College of William \& Mary's Institutional Animal Care and Use Committee.

\section{Laboratory procedures}

As with the field methods, most of the laboratory procedures associated with determination of age and disease status for striped bass were described previously by Gauthier et al. (2008). Ages were determined by reading a transverse section of the right sagittal otolith under transmitted light with $25 \times$ magnification, and year-class ages were assigned based on the conventional 1 January birth date. Disease status was determined by the presence of granulomas in histologic sections of spleen. Assessment of disease severity, which was not described by Gauthier et al. (2008), involved taking splenic area $\left(\mathrm{mm}^{2}\right)$ measurements by photographing sections at $6.3 \times$ magnification on a dissecting microscope equipped with a digital camera. Splenic area was calibrated and measured with MetaMorph software (Universal Imaging, Downingtown, Pennsylvania), and area measurements were taken on all sections examined for granulomas, excluding fish with no granulomas. A disease severity index (SI) was calculated as $\log _{10}$ (granulomas $\cdot \mathrm{mm}^{-2}+1$ ).

\section{Growth models, parameter estimation, and inference}

Models such as the von Bertalanffy function (von Bertalanffy 1938), allometric power equation, and resultant model when these two equations are combined are commonly applied in the analysis of fish growth data (Quinn and Deriso 1999). The parameters of these models represent populationlevel means that reflect the combined effects of natural and sampling sources of variation. Evaluating the importance of categorical covariates on growth model parameter estimates has traditionally been a two-stage and somewhat cumbersome process. First, separate growth models would need to be fitted to subsets of data corresponding to the level(s) of the covariate(s) of interest. Post-hoc tests of equality among estimated parameters using either univariate (e.g., FisherBerhens) or multivariate (e.g., Hotelling $T^{2}$ ) test statistics would then need to be conducted for statistical inference (Quinn and Deriso 1999). Recently, however, Kimura (2008) described how parameters of growth models can be estimated 
Fig. 1. Sampling locations in Chesapeake Bay where striped bass (Morone saxatilis) were captured by the ChesMMAP survey during March 2007. A comparable spatial coverage of samples was achieved during each research cruise of the study. Inset shows the location of the study area on the US Atlantic coast.



in a general fixed-effects nonlinear modeling framework that allows for straightforward significance testing of covariates and efficient model comparisons. We adopted this approach in our modeling of striped bass growth data.

For each of the three classes of models considered in the analysis of striped bass growth data, preliminary model fits assuming both additive and multiplicative error structure were assessed via visual inspection of normal $Q Q$ plots of residuals and plots of residuals against the independent variable. For the length-at-age analysis, models fitted assuming additive error yielded slightly better diagnostic plots of normality, but there were clear patterns of increasing variance in length with age. Accordingly, all length-at-age models were fitted with additive error, and heteroscedasticity was dealt with by using weighting least squares in which the weighting term for a given observation was the inverse of the sample variance at that age. This approach makes the implicit assumption that samples collected adequately represent the nature of the variance of length-at-age, at least up to a constant of proportionality (Davidian and Giltinan 1995). For the eviscerated mass-at-length and eviscerated mass-atage age analyses, the assumptions of normality and constant variance of residuals were much more plausible given a multiplicative error structure, so all parameterizations of these models reflected a $\log _{\mathrm{e}}$ transformation.

The von Bertalanffy growth model was used to model the striped bass length-at-age data, and the fixed-effects form with additive error is given by 


$$
l_{i}=l_{\infty i}\left(1-\mathrm{e}^{-k_{i}\left(t_{i}-t_{0 i}\right)}\right)+\varepsilon_{i}
$$

where for the $i$ th individual fish, $l_{\infty i}$ is the asymptotic length, $k_{i}$ is the instantaneous growth coefficient, $t_{0 i}$ is the theoretical age at length zero, $\varepsilon_{i}$ is the error term, and

$$
\left(\begin{array}{c}
l_{\infty i} \\
k_{i} \\
t_{0 i}
\end{array}\right)=\left(\begin{array}{l}
\beta_{0 l_{\infty}}+x_{i 1} \beta_{1 l_{\infty}}+\cdots+x_{i q} \beta_{q l_{\infty}} \\
\beta_{0 k}+x_{i 1} \beta_{1 k}+\cdots+x_{i q} \beta_{q k} \\
\beta_{0 t_{0}}+x_{i 1} \beta_{1 t_{0}}+\cdots+x_{i q} \beta_{q t_{0}}
\end{array}\right)
$$

where $x_{i j}$ is the $j$ th covariate with coefficients $\beta_{j l_{\infty}}, \beta_{j k}$, and $\beta_{j t_{0}}$. Five parameterizations of the von Bertalanffy model (vB) were considered: $M_{v B 1}$ included no covariates, $M_{v B 2}$ contained only sex as a covariate, $\mathrm{M}_{\mathrm{VB} 3}$ included only disease status as a covariate, $\mathrm{M}_{\mathrm{vB} 4}$ contained both sex and disease status covariates, and $\mathrm{M}_{\mathrm{vB} 5}$ contained sex, disease status, and severity as covariates.

Striped bass eviscerated mass-at-length data were modeled with the allometric power function assuming multiplicative error:

$$
\log _{\mathrm{e}}\left(w_{i}\right)=\log _{\mathrm{e}}\left(\alpha_{i}\right)+\gamma_{i} \log _{\mathrm{e}}\left(l_{i}\right)+\varepsilon_{i}
$$

where for the $i$ th individual, $\alpha_{i}$ is a constant (sometimes referred to as a condition factor), $\gamma_{i}$ is the slope parameter, $\varepsilon_{i}$ is the error term, and

$$
\left(\begin{array}{l}
\alpha_{\mathrm{i}} \\
\gamma_{\mathrm{i}}
\end{array}\right)=\left(\begin{array}{c}
\beta_{0 \alpha}+x_{i 1} \beta_{1 \alpha}+\cdots+x_{i q} \beta_{q \alpha} \\
\beta_{0 \gamma}+x_{i 1} \beta_{1 \gamma}+\cdots+x_{i q} \beta_{q \gamma}
\end{array}\right)
$$

where $x_{i j}$ is the $j$ th covariate with coefficients $\beta_{j \alpha}$ and $\beta_{j \gamma}$. Eleven parameterizations of the allometric model (al) were considered: $\mathrm{M}_{\mathrm{al} 1}$ included no covariates, $\mathrm{M}_{\mathrm{al} 2}$ contained only sex as a covariate, $\mathrm{M}_{\mathrm{al} 3}$ included only disease status as a covariate, $\mathrm{M}_{\mathrm{al} 4}$ contained both sex and disease status as covariates, $\mathrm{M}_{\mathrm{al} 5}$ contained sex, disease status, and severity as covariates, $\mathrm{M}_{\mathrm{a} 16}$ contained cruise as a covariate where cruises within a year were treated separately and data were pooled across years, $\mathrm{M}_{\mathrm{a} 17}$ contained cruise and disease status as covariates, $\mathbf{M}_{\mathrm{al} 8}$ contained cruise, disease status, and severity as covariates, $\mathrm{M}_{\mathrm{a} 19}$ contained year-cruise as a covariate where each cruise across the five-year time series was treated separately, $\mathbf{M}_{\mathrm{al} 10}$ contained both year-cruise and disease status covariates, and $\mathrm{M}_{\mathrm{al11}}$ contained year-cruise, disease status, and severity as covariates. Cruise and year-cruise were used as proxies for time to investigate if the relationship among eviscerated mass and length changed intra- and interannually, respectively.

Striped bass eviscerated mass-at-age data were modeled by combining the von Bertalanffy and allometric equations. The von Bertalanffy - allometric (vB-al) function under multiplicative error is

$$
\log _{\mathrm{e}}\left(w_{i}\right)=\log _{\mathrm{e}}\left(w_{\infty i}\right)+\gamma_{i} \log _{\mathrm{e}}\left(1-\mathrm{e}^{-k_{i}\left(t_{i}-t_{0 i}\right)}\right)+\varepsilon_{i}
$$

where for the $i$ th individual fish, $w_{\infty i}$ is the asymptotic eviscerated mass, all other parameters are defined above, $\varepsilon_{i}$ is the error term, and

$$
\left(\begin{array}{c}
w_{\infty i} \\
k_{i} \\
t_{0 i}
\end{array}\right)=\left(\begin{array}{l}
\beta_{0 l_{\infty}}+x_{i 1} \beta_{1 l_{\infty}}+\cdots+x_{i q} \beta_{q l_{\infty}} \\
\beta_{0 k}+x_{i 1} \beta_{1 k}+\cdots+x_{i q} \beta_{q k} \\
\beta_{0 t_{0}}+x_{i 1} \beta_{1 t_{0}}+\cdots+x_{i q} \beta_{q t_{0}}
\end{array}\right)
$$

where $x_{i j}$ is the $j$ th covariate with coefficients $\beta_{j w_{\infty}}, \beta_{j k}$, and $\beta_{j t_{0}}$. In our application of eq. 3 , the parameter $\gamma_{i}$ was not estimated explicitly because of difficulty obtaining reliable results when it was included in the model (Quinn and Deriso 1999). For each parameterization, $\gamma_{i}$ was fixed at the estimate obtained from the respective eviscerated mass-at-length model. The five model parameterizations used in the lengthat-age analysis were also considered for the von Bertalanffy allometric function, denoted as $\mathrm{M}_{\mathrm{vB}-\mathrm{al} 1}, \mathrm{M}_{\mathrm{vB}-\mathrm{al} 2}, \mathrm{M}_{\mathrm{vB}-\mathrm{al} \text {, }}$, $\mathrm{M}_{\mathrm{vB}-\mathrm{al} 4}$, and $\mathrm{M}_{\mathrm{vB}-\mathrm{al} 5 \text {. }}$

In eqs. $1-3$, the estimates of the $\beta_{j}$ s represent how much a particular covariate increases or decreases the model prediction given by the $\beta_{0} \mathrm{~s}$, which are based on the reference levels of the covariates. For the covariates considered, male striped bass were set as the reference sex, disease-negative fish were set as the reference disease status, and March 2003 was set as the reference time period. All models were fitted with the software package R (version 2.11.0; R Core Development Team 2010), and model comparisons were conducted separately using an information theoretic approach (Akaike 1973; Burnham and Anderson 2002). Although Akaike's information criterion (AIC) was derived from likelihood theory, it can be expressed as a function of residual sums-of-squares (RSS):

$$
\mathrm{AIC}=n\left(1+\log _{\mathrm{e}}(2 \pi \cdot \mathrm{RSS} / n)\right)+2 p
$$

where $n$ is the number of data points and $p$ is the number of estimated parameters (Kimura 2008). Note that for the length-at-age models where weight least squares was used, the AIC values from eq. 4 will not be exact. However, model comparisons are valid as all models under consideration have the same underlying log-likelihood function. The most parsimonious model of a given set has the lowest AIC value, and because AIC is on a relative scale, it is important to calculate AIC differences $(\triangle \mathrm{AIC})$ :

$$
\triangle \mathrm{AIC}=\mathrm{AIC}-\mathrm{AIC}_{\min }
$$

where $\mathrm{AIC}_{\text {min }}$ is the smallest $\mathrm{AIC}$ value within the candidate set of models. Generally, $\triangle \mathrm{AIC}$ values between 0 and 2 are indicative of substantial empirical support for the fitted model, values between 4 and 7 are associated with models that have considerably less empirical support, and values $>$ 10 suggest virtually no empirical support (Burnham and Anderson 2002).

\section{Results}

\section{Apparent prevalence and severity}

From 2003 to 2007, a total of 2300 striped bass were processed for disease and age determination. The majority of these fish were male ( $n=1500$ summed over ages and disease status), disease-positive ( $n=1241$ summed over ages and sexes), and between age- 1 and age-5 ( $n=2008$ summed over sexes and disease status). Apparent prevalence of mycobacteriosis in male striped bass increased with age, plateaued 
Fig. 2. Age-specific apparent prevalence of mycobacteriosis for female (dark grey bars) and male (light grey bars) striped bass (Morone saxatilis) collected by the ChesMMAP survey during 2003-2007. Sample size for each age class is shown above each bar.

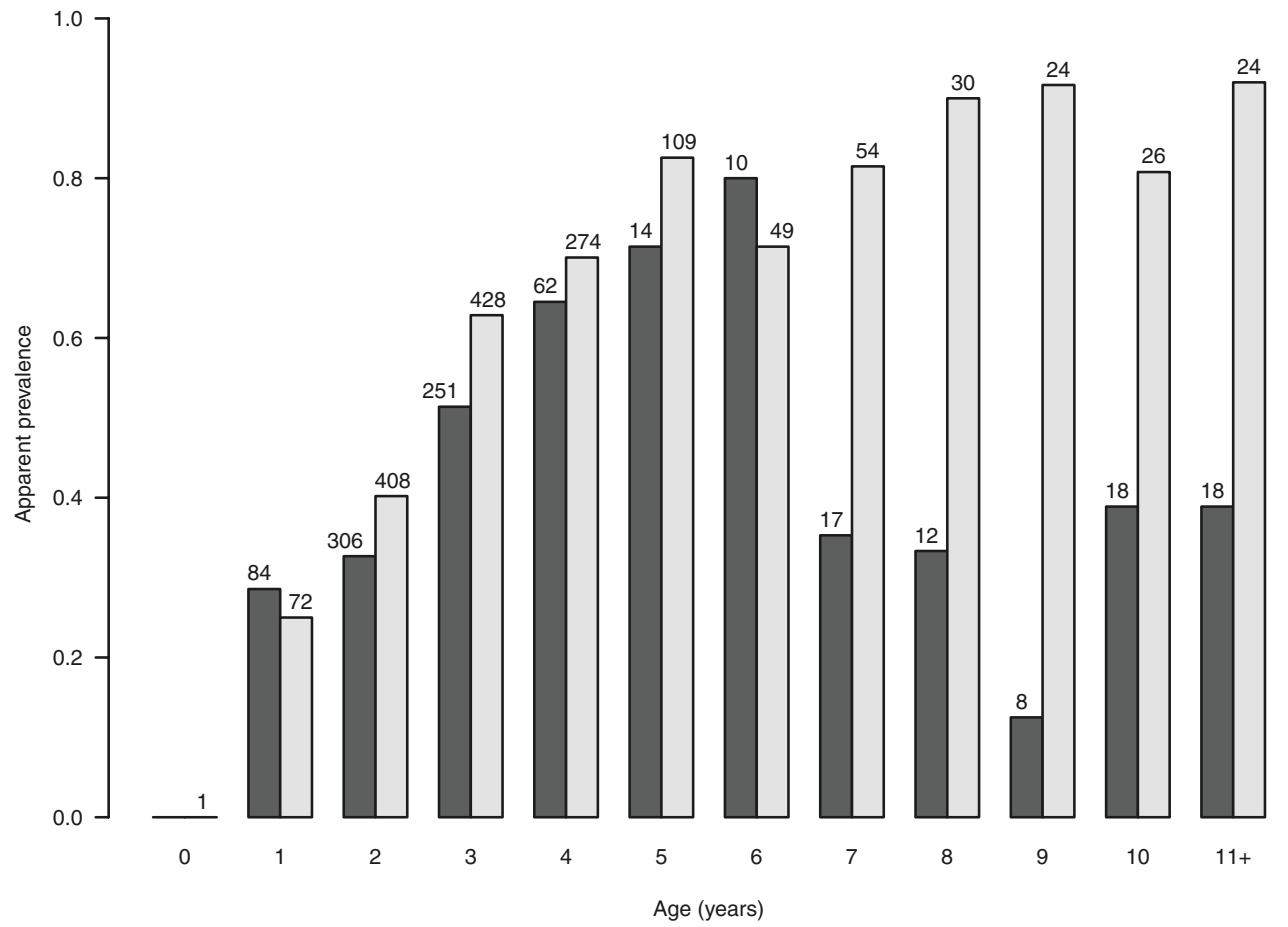

by age-5, and ranged from 0.71 to 0.92 thereafter (Fig. 2). For female striped bass, apparent prevalence increased with age and peaked at 0.80 by age- 6 , followed by a marked decline for older fish.

For female striped bass, level 1 of the severity index (SI) increased with age until age-5 and varied between $12.5 \%$ and $38.9 \%$ thereafter (Fig. $3 a$ ). SI levels 2 and 3 showed similar patterns, and both peaked at age-6. For male striped bass, all nonzero levels of SI generally increased as a function of age, with level 1 showing the highest percentages (Fig. $3 b$ ). Fish exhibiting SI levels 2 and 3 comprised about $13.5 \%$ of each age class on average.

\section{Length-at-age modeling}

Fork length (FL) and age data from the aforementioned 2300 striped bass were used in the length-at-age analysis, and the four von Bertalanffy model parameterizations considered were successfully fitted to the observed data. Based on $\mathrm{AIC}$, and thus $\triangle \mathrm{AIC}$, the model with both sex and disease status as covariates (i.e., $\mathrm{M}_{\mathrm{vB} 4}$ ) provided the best fit to the data; however, there was also empirical support for the model that included the sex, disease status, and severity covariates (i.e., $\mathrm{M}_{\mathrm{vB} 5}$; Table 1). Compared with the null model, inclusion of sex as an additional explanatory variable yielded a considerably better fit, which corroborates documented sexual dimorphism in striped bass age and growth (Setzler et al. 1980; Collette and Klein-MacPhee 2002).

The estimate of the disease status coefficient for $l_{\infty}$ from model $\mathrm{M}_{\mathrm{vB} 4}$ was negative and statistically significant, which suggests that the predicted asymptotic length of diseasepositive fish is lower than that of disease-negative fish irrespective of sex (Table 2). The presence of mycobacteriosis is therefore associated with negative impacts on the growth of striped bass in Chesapeake Bay, as measured by relating
Fig. 3. Age-specific mycobacteriosis severity for (a) female and (b) male striped bass (Morone saxatilis) collected by the ChesMMAP survey during 2003-2007. Severity category (Sevcat) was assigned based on the following granuloma densities: Sevcat $=0$ if severity index $(\mathrm{SI})=0$ (solid circle); Sevcat $=1$ if $0<\mathrm{SI} \leq 0.1$ (open circle); Sevcat $=2$ if $0.1<\mathrm{SI} \leq 0.5$ (solid triangle); and Sevcat $=3$ if SI $>0.5$ (open triangle).

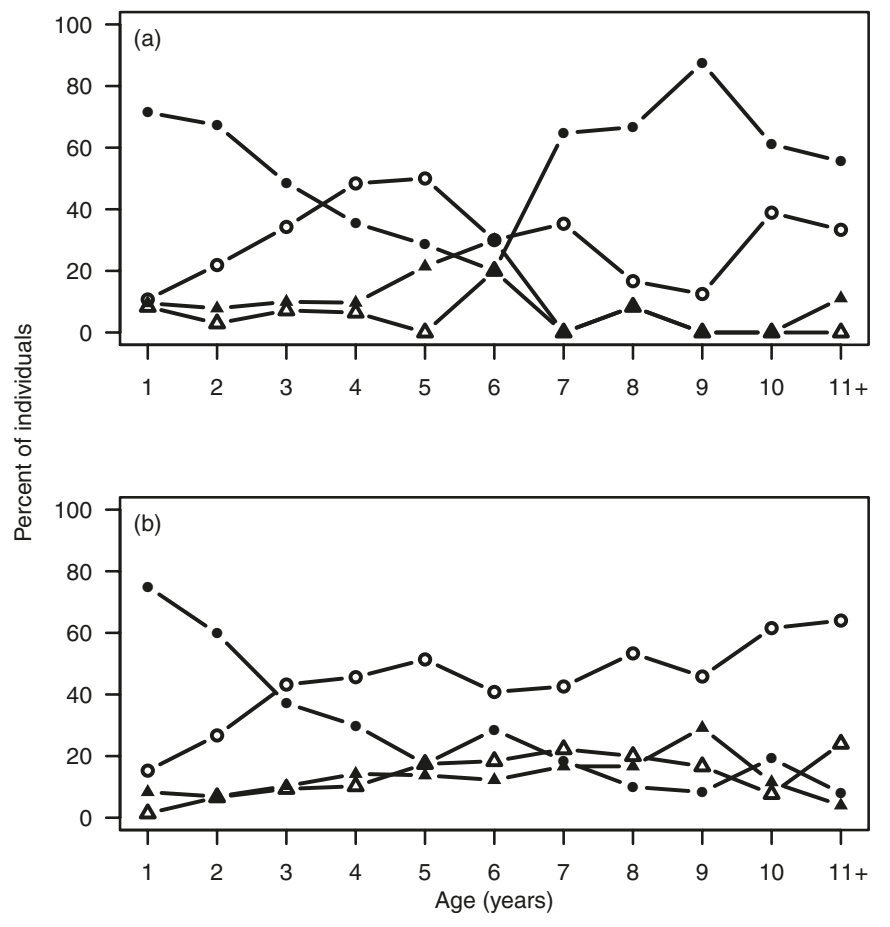

length to age. In general, the estimated standard errors of the parameter estimates from model $\mathrm{M}_{\mathrm{vB} 4}$ were low as all 
Table 1. Residual sum-of-squares (RSS), Akaike's information criterion (AIC), and $\triangle \mathrm{AIC}$ for models $\mathrm{M}_{\mathrm{vB} 1}$, $\mathrm{M}_{\mathrm{vB} 2}, \mathrm{M}_{\mathrm{vB} 3}, \mathrm{M}_{\mathrm{vB} 4}$, and $\mathrm{M}_{\mathrm{vB} 5}$ fitted to striped bass (Morone saxatilis) length-at-age data collected in the mainstem of Chesapeake Bay.

\begin{tabular}{lllcrr}
\hline & & & No. of \\
Model & Covariates & RSS & parameters & AIC & $\Delta$ AIC \\
\hline $\mathrm{M}_{\mathrm{vB} 1}$ & None & 2314.6 & 4 & 6549.7 & 153.9 \\
$\mathrm{M}_{\mathrm{vB} 2}$ & Sex & 2265.6 & 7 & 6506.5 & 110.7 \\
$\mathrm{M}_{\mathrm{vB} 3}$ & Disease status & 2214.2 & 7 & 6453.7 & 58.0 \\
$\mathrm{M}_{\mathrm{vB} 4}$ & Disease status, sex & 2153.5 & 10 & 6395.7 & 0.0 \\
$\mathrm{M}_{\mathrm{vB} 5}$ & Disease status, sex, severity & 2150.0 & 13 & 6398.0 & 2.3 \\
\hline
\end{tabular}

Table 2. Parameter estimates, standard errors (SE), and coefficients of variation $(\mathrm{CV})$ from model $\mathrm{M}_{\mathrm{vB} 4}$ fitted to length-at-age data from striped bass (Morone saxatilis) collected in the mainstem of Chesapeake Bay (striped bass that were male and disease-negative were the reference levels of the covariates).

\begin{tabular}{llccr}
\hline Type & Parameter & Estimate & SE & CV \\
\hline Constant & $\beta_{0 l_{\infty}}$ & 1754.4 & 218.4 & 0.12 \\
& $\beta_{0 k}$ & 0.04 & 0.006 & 0.15 \\
\multirow{4}{*}{ Sex } & $\beta_{0 t_{0}}$ & -3.14 & 0.21 & -0.07 \\
& $\beta_{1 l_{\infty}}$ & 124.9 & 30.3 & 0.24 \\
& $\beta_{1 k}$ & 0.0077 & 0.002 & -0.26 \\
Disease status & $\beta_{1 t_{0}}$ & 1.38 & 0.16 & 0.11 \\
& $\beta_{2 l_{\infty}}$ & -748.5 & 242.4 & -0.32 \\
& $\beta_{2 k}$ & 0.037 & 0.01 & 0.27 \\
& $\beta_{2 t_{0}}$ & -0.15 & 0.30 & -2.00 \\
\hline
\end{tabular}

but one of the coefficient of variations $(\mathrm{CV})$ were less than 0.30. Plots of predicted length-at-age from $\mathrm{M}_{\mathrm{vB} 4}$ over the observed data separated by sex show a slight increased mean length for disease-positive fish at younger ages (those age-0 to age-5), followed by a clear reduction in mean length at older ages (those age-6+; Figs. 4a, 4b).

\section{Eviscerated mass-at-length modeling}

Eviscerated mass-at-length data were available from 2398 striped bass ranging from $124 \mathrm{~mm}$ FL to $1010 \mathrm{~mm} \mathrm{FL}$, and all allometric power model parameterizations specified were successfully fitted to the observed data. As indicated by the $\triangle \mathrm{AIC}$ values, the model parameterizations that included year-cruise as a covariate (regardless of the inclusion of other covariates) provided substantially better fits to the data than any other models (Table 3). Not surprisingly, the data suggest that the eviscerated mass-at-length relationship varies over the years of data in the analysis. Among the model parameterizations that included the year-cruise covariate (i.e., models $\mathrm{M}_{\mathrm{al} 9}, \mathrm{M}_{\mathrm{al10}}$, and $\mathrm{M}_{\mathrm{al11}}$ ), comparisons of the $\triangle \mathrm{AIC}$ values for models $\mathrm{M}_{\mathrm{al} 9}$ and $\mathrm{M}_{\mathrm{al} 10}$ showed that both fit the data equally well. This result suggests that modeling simply the presence of disease did little to alter model fit. However, when disease severity was added as a covariate, model fit substantially improved such that model $\mathrm{M}_{\text {al11 }}$ provided the best overall fit to the data.

The estimates of the severity coefficients for $\alpha$ and $\gamma$ from model $\mathrm{M}_{\mathrm{al11}}$ were positive and negative, respectively, with the former not statistically significant. The statistical significance of the coefficient $\gamma$ is likely linked to the improved AIC value of $\mathrm{M}_{\mathrm{al11}}$ relative to the other models and suggests that disease severity as measured through the density of splenic
Fig. 4. Observed length-at-age and predicted von Bertalanffy growth curves derived from parameter estimates associated with model $\mathrm{M}_{\mathrm{vB} 4}$ for $(a)$ female and $(b)$ male striped bass (Morone saxatilis) collected by the ChesMMAP survey during 2003-2007. In both panels, solid circles and the solid line correspond to disease-negative fish, and shaded circles and the shaded line represent diseasepositive fish.

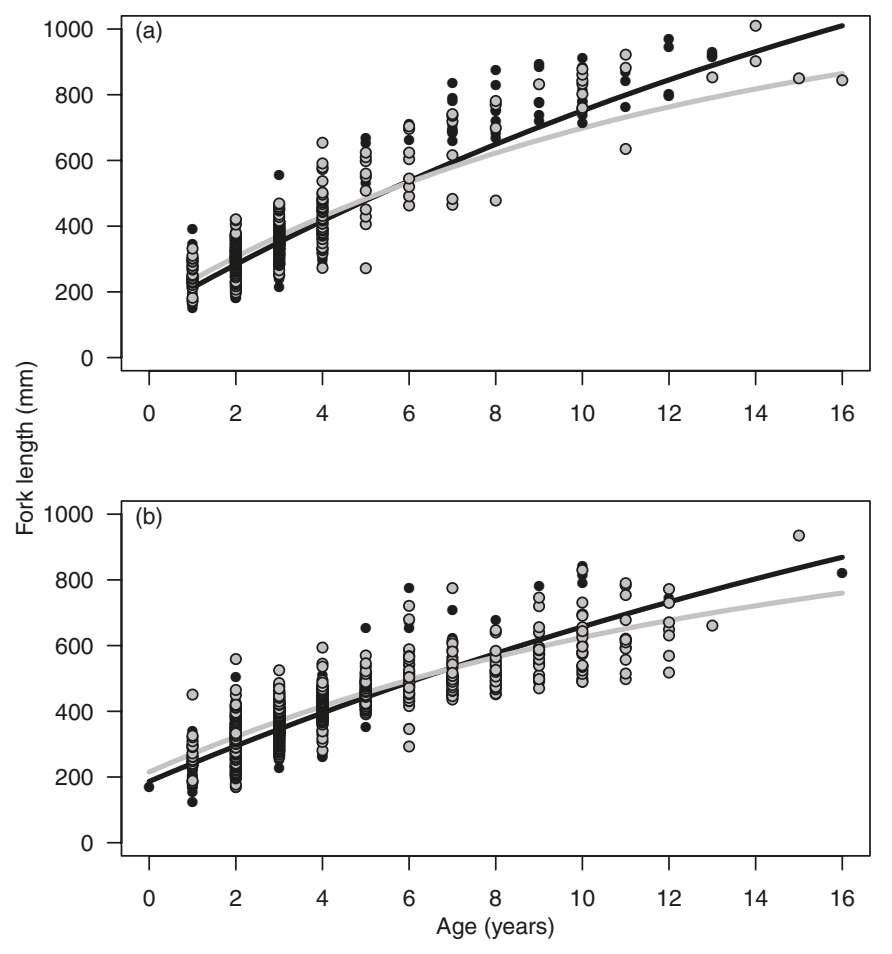

granulomas reduces the slope of eviscerated mass accumulation with length. In general, however, the parameter estimates derived from model $M_{\text {al11 }}$ were not precise, with $42 \%$ of the CVs greater than or equal to 0.51 (Table 4). This lack of precision was likely due to the data from each cruise being treated separately, as defined by the year-cruise covariate. Mean sample size across all cruises was 99.5 fish, and less than 50 striped bass in total were captured in 10 of the 24 cruises, so many of the estimated coefficients of the yearcruise covariate were based on few fish. The estimated effects on the condition factor parameter $\alpha$ relative to the intercept (adjusted to include the disease status and severity effects) over the time series of the study showed an increase in 2003 followed by a reduced and variable pattern thereafter (Fig. 5a). The estimated effects on slope parameter $\gamma$ showed a decrease during the first year to the low point in May 2004 
Table 3. Residual sum-of-squares (RSS), Akaike's information criterion (AIC), and $\Delta$ AIC for models $M_{a l 1}, M_{a l 2}, M_{a l 3}, M_{a 14}$, $\mathrm{M}_{\mathrm{a} 15}, \mathrm{M}_{\mathrm{al} 6}, \mathrm{M}_{\mathrm{al} 7}, \mathrm{M}_{\mathrm{a} 18}, \mathrm{M}_{\mathrm{al} 9}, \mathrm{M}_{\mathrm{al} 10}$, and $\mathrm{M}_{\mathrm{al11}}$ fitted to striped bass (Morone saxatilis) eviscerated mass-at-length data collected in the mainstem of Chesapeake Bay.

\begin{tabular}{|c|c|c|c|c|c|}
\hline Model & Covariates & RSS & No. of parameters & AIC & $\Delta \mathrm{AIC}$ \\
\hline$\overline{\mathrm{M}_{\mathrm{al} 1}}$ & None & 23.9 & 3 & -4219.9 & 784.9 \\
\hline $\mathrm{M}_{\mathrm{al} 2}$ & Sex & 23.8 & 5 & -4222.6 & 782.1 \\
\hline $\mathrm{M}_{\mathrm{al} 3}$ & Disease status & 23.7 & 5 & -4226.7 & 778.0 \\
\hline $\mathrm{M}_{\mathrm{al} 4}$ & Disease status, sex & 23.7 & 7 & -4231.5 & 773.2 \\
\hline $\mathrm{M}_{\mathrm{a} 15}$ & Disease status, sex, severity & 23.5 & 9 & -4241.3 & 763.5 \\
\hline $\mathrm{M}_{\mathrm{al6}}$ & Cruise & 19.8 & 11 & -4651.3 & 353.5 \\
\hline $\mathrm{M}_{\mathrm{al} 7}$ & Cruise, disease status & 19.7 & 13 & -4661.1 & 343.6 \\
\hline $\mathrm{M}_{\mathrm{al} 8}$ & Cruise, disease status, severity & 19.6 & 15 & -4667.9 & 336.9 \\
\hline $\mathrm{M}_{\mathrm{al} 9}$ & Year-cruise & 16.6 & 49 & -4997.8 & 6.9 \\
\hline $\mathrm{M}_{\mathrm{al} 10}$ & Year-cruise, disease status & 16.6 & 51 & -4996.9 & 7.9 \\
\hline $\mathrm{M}_{\mathrm{al} 11}$ & Year-cruise, disease status, severity & 16.5 & 53 & -5004.8 & 0.0 \\
\hline
\end{tabular}

followed by a slight increase to a generally constant level (Fig. 5b).

\section{Eviscerated mass-at-age modeling}

Eviscerated mass and age data were available for 2272 striped bass, and of the five von Bertalanffy - allometric parameterizations fitted successfully, the $\triangle$ AIC values indicated that the model with sex and disease status as covariates provided the best description of the data (i.e., model $\mathrm{M}_{\mathrm{vB}-\mathrm{al} 4}$; Table 5). The other model parameterizations considered received no empirical support. Relative to the null model, the inclusion of the sex covariate again yielded a better fit, which is consistent with the results of the length-at-age modeling and further suggestive of sexually dimorphic growth (Setzler et al. 1980; Collette and Klein-MacPhee 2002).

The estimated disease status coefficients for $w_{\infty}$ and $k$ from model $\mathrm{M}_{\mathrm{vB}-\mathrm{al} 4}$ were both negative and statistically significant, which indicates that the estimated asymptotic mass of disease-positive fish and the rate at which these fish approach their $w_{\infty}$ are less than those of disease-negative fish (Table 6). The presence of mycobacteriosis therefore negatively impacts the growth of striped bass in Chesapeake Bay, as measured by relating eviscerated mass to age. The precision of the model $\mathrm{M}_{\mathrm{vB}-\mathrm{a} 44}$ parameter estimates was generally good as all but one of the CVs in absolute value ranged between 0.10 and 0.42 . Plots of model $\mathrm{M}_{\mathrm{vB}-\mathrm{al} 4}$ fits over the observed data separated by sex show a reduction in predicted eviscerated mass-at-age after age- 6 for male and female striped bass (Figs. 6a, 6b).

\section{Discussion}

The primary objective of this study was to examine the impacts of mycobacteriosis on the growth of striped bass in Chesapeake Bay (as opposed to providing "true" growth model parameter estimates), and our results suggest that growth of disease-positive fish is significantly different than that of disease-negative fish. Based on the fits of the eviscerated mass-at-length models with the year-cruise covariate, the underlying allometric relationship of striped bass appears to be marginally affected by simply the presence of disease, and only differs significantly among the disease groups when disease severity becomes high. However, the eviscerated mass-at-length relationship does not provide insight into the time that it takes a particular fish to attain a given size, and when size-at-age was examined, the results showed large differences in the asymptotic values for the two disease groups. Disease-positive fish therefore appear to grow more slowly than disease-negative fish, which indicates that diseasepositive striped bass within the Chesapeake Bay experience compromised biomass accumulation when compared with disease-negative fish.

For the eviscerated mass-at-length analysis, the size ranges of fish collected varied on each cruise such that not all length classes were represented within the levels of the year-cruise covariate. The minimum lengths of fish by year-cruise were relatively stable over the time series (mean (standard error, $\mathrm{SE})=211.5 \mathrm{~mm}(10.1 \mathrm{~mm})$ ); however, the maximum lengths were more variable (mean $(\mathrm{SE})=762.4 \mathrm{~mm}(31.2 \mathrm{~mm})$ ). The causal mechanism of this variability in length is likely the ontogenetic migratory patterns of striped bass and the unavailability of larger fish in Chesapeake Bay during the summer (Kohlenstein 1981; Dorazio et al. 1994). Poor representation of larger fish during summer cruises combined with the relatively low sample sizes for some sampling events may have biased the estimated parameters. If the candidate model set was restricted to include parameterizations that did not include temporal variables, the AIC values suggest that the model with sex, disease status, and severity as covariates would receive all the empirical support (i.e., model $\mathrm{M}_{\mathrm{al} 5}$ ), and the conclusion would again be that the presence and severity of disease influences the allometric relationships of the two disease groups. However, the degree to which disease and temporal effects on the eviscerated mass-at-length relationship of striped bass are confounded requires additional investigation.

When interpreting results derived from the general fixedeffect modeling framework, it is important to distinguish between model covariates and the causal mechanisms underlying these variables (Kimura 2008). Our results indicate that female striped bass attain larger sizes-at-age than male fish, and as stated previously, disease-positive fish grow more slowly than disease-negative fish. Sexually dimorphic growth in striped bass is well accepted (Setzler et al. 1980; Collette and Klein-MacPhee 2002) and can serve to validate the significance of the sex effect in our study. However, the significance of the disease status covariate represents a new finding that should be considered carefully in the context of the 
Table 4. Parameter estimates, standard errors (SE), and coefficients of variation (CV) from model $\mathrm{M}_{\mathrm{al11}}$ fitted to eviscerated mass-at-length data from striped bass (Morone saxatilis) collected in the mainstem of Chesapeake Bay (striped bass that were disease-negative and captured in March 2003 were the reference levels of the categorical covariates).

\begin{tabular}{|c|c|c|c|c|}
\hline Type & Parameter & Estimate & SE & $\mathrm{CV}$ \\
\hline \multirow[t]{2}{*}{ Constant } & $\beta_{0 \alpha}$ & $9.32 \times 10^{-9}$ & $1.04 \times 10^{-9}$ & 0.11 \\
\hline & $\beta_{0 \gamma}$ & 3.03 & 0.019 & 0.01 \\
\hline \multirow[t]{2}{*}{ Disease status } & $\beta_{1 \alpha}$ & $-1.27 \times 10^{-10}$ & $7.40 \times 10^{-11}$ & -0.58 \\
\hline & $\beta_{1 \gamma}$ & 0.0016 & 0.0015 & 0.94 \\
\hline \multirow[t]{2}{*}{ Severity } & $\beta_{2 \alpha}$ & $6.70 \times 10^{-11}$ & $3.42 \times 10^{-11}$ & 0.51 \\
\hline & $\beta_{2 \gamma}$ & -0.0017 & 0.0006 & -0.35 \\
\hline \multirow[t]{2}{*}{ May 2003} & $\beta_{3 \alpha}$ & $2.54 \times 10^{-8}$ & $1.41 \times 10^{-8}$ & 0.56 \\
\hline & $\beta_{3 \gamma}$ & -0.21 & 0.070 & -0.33 \\
\hline \multirow[t]{2}{*}{ July 2003} & $\beta_{4 \alpha}$ & $3.03 \times 10^{-8}$ & $1.90 \times 10^{-8}$ & 0.63 \\
\hline & $\beta_{4 \gamma}$ & -0.23 & 0.082 & -0.36 \\
\hline \multirow[t]{2}{*}{ Sept. 2003} & $\beta_{5 \alpha}$ & $1.34 \times 10^{-8}$ & $1.14 \times 10^{-8}$ & 0.85 \\
\hline & $\beta_{5 \gamma}$ & 0.17 & 0.086 & -0.51 \\
\hline \multirow[t]{2}{*}{ Nov. 2003} & $\beta_{6 \alpha}$ & $4.31 \times 10^{-8}$ & $1.53 \times 10^{-8}$ & 0.35 \\
\hline & $\beta_{6 \gamma}$ & -0.30 & 0.053 & -0.18 \\
\hline \multirow[t]{2}{*}{ Mar. 2004} & $\beta_{7 \alpha}$ & $2.43 \times 10^{-9}$ & $1.64 \times 10^{-9}$ & 0.67 \\
\hline & $\beta_{7 \gamma}$ & -0.033 & 0.026 & -0.81 \\
\hline \multirow[t]{2}{*}{ May 2004} & $\beta_{8 \alpha}$ & $5.90 \times 10^{-9}$ & $4.22 \times 10^{-9}$ & 0.71 \\
\hline & $\beta_{8 \gamma}$ & -0.074 & 0.048 & -0.65 \\
\hline \multirow[t]{2}{*}{ July 2004} & $\beta_{9 \alpha}$ & $-3.57 \times 10^{-9}$ & $1.96 \times 10^{-9}$ & -0.55 \\
\hline & $\beta_{9 \gamma}$ & 0.076 & 0.051 & 0.68 \\
\hline \multirow[t]{2}{*}{ Sept. 2004} & $\beta_{10 \alpha}$ & $-5.28 \times 10^{-9}$ & $1.74 \times 10^{-9}$ & -0.33 \\
\hline & $\beta_{10 \gamma}$ & 0.12 & 0.062 & 0.51 \\
\hline \multirow[t]{2}{*}{ Nov. 2004} & $\beta_{11 \alpha}$ & $-1.95 \times 10^{-9}$ & $1.40 \times 10^{-9}$ & -0.72 \\
\hline & $\beta_{11 \gamma}$ & 0.021 & 0.029 & 1.40 \\
\hline \multirow[t]{2}{*}{ Mar. 2005} & $\beta_{12 \alpha}$ & $-3.69 \times 10^{-9}$ & $1.16 \times 10^{-9}$ & -0.32 \\
\hline & $\beta_{12 \gamma}$ & 0.083 & 0.025 & 0.30 \\
\hline \multirow[t]{2}{*}{ May 2005} & $\beta_{13 \alpha}$ & $5.68 \times 10^{-9}$ & $2.23 \times 10^{-9}$ & 0.39 \\
\hline & $\beta_{13 \gamma}$ & -0.87 & 0.029 & -0.34 \\
\hline \multirow[t]{2}{*}{ July 2005} & $\beta_{14 \alpha}$ & $-4.91 \times 10^{-9}$ & $1.50 \times 10^{-9}$ & -0.31 \\
\hline & $\beta_{14 \gamma}$ & 0.13 & 0.047 & 0.35 \\
\hline \multirow[t]{2}{*}{ Sept. 2005} & $\beta_{15 \alpha}$ & $3.72 \times 10^{-9}$ & $3.88 \times 10^{-9}$ & 1.04 \\
\hline & $\beta_{15 \gamma}$ & -0.072 & 0.053 & -0.73 \\
\hline \multirow[t]{2}{*}{ Nov. 2005} & $\beta_{16 \alpha}$ & $4.90 \times 10^{-10}$ & $2.11 \times 10^{-9}$ & 4.31 \\
\hline & $\beta_{16 \gamma}$ & -0.016 & 0.037 & -2.28 \\
\hline \multirow[t]{2}{*}{ Mar. 2006} & $\beta_{17 \alpha}$ & $4.93 \times 10^{-9}$ & $1.64 \times 10^{-9}$ & 0.33 \\
\hline & $\beta_{17 \gamma}$ & -0.065 & 0.024 & -0.37 \\
\hline \multirow[t]{2}{*}{ May 2006} & $\beta_{18 \alpha}$ & $-3.25 \times 10^{-10}$ & $3.62 \times 10^{-9}$ & -11.17 \\
\hline & $\beta_{18 \gamma}$ & 0.011 & 0.068 & 6.26 \\
\hline \multirow[t]{2}{*}{ July 2006} & $\beta_{19 \alpha}$ & $6.77 \times 10^{-9}$ & $7.74 \times 10^{-9}$ & 1.14 \\
\hline & $\beta_{19 \gamma}$ & -0.096 & 0.082 & -0.86 \\
\hline Sept. 2006 & $\beta_{20 \alpha}$ & $-5.30 \times 10^{-9}$ & $1.73 \times 10^{-9}$ & -0.33 \\
\hline & $\beta_{20 \gamma}$ & 0.12 & 0.060 & 0.49 \\
\hline Nov. 2006 & $\beta_{21 \alpha}$ & $-2.76 \times 10^{-9}$ & $1.41 \times 10^{-9}$ & -0.51 \\
\hline & $\beta_{21 \gamma}$ & 0.046 & 0.031 & 0.68 \\
\hline Mar. 2007 & $\beta_{22 \alpha}$ & $1.14 \times 10^{-10}$ & $1.53 \times 10^{-9}$ & 13.40 \\
\hline & $\beta_{22 \gamma}$ & 0.0017 & 0.028 & 15.98 \\
\hline May 2007 & $\beta_{23 \alpha}$ & $-8.84 \times 10^{-11}$ & $2.06 \times 10^{-9}$ & -23.35 \\
\hline & $\beta_{23 \gamma}$ & -0.0011 & 0.038 & -33.19 \\
\hline July 2007 & $\beta_{24 \alpha}$ & $-6.32 \times 10^{-10}$ & $2.89 \times 10^{-9}$ & -4.58 \\
\hline & $\beta_{24 \gamma}$ & 0.028 & 0.056 & 19.75 \\
\hline Nov. 2007 & $\beta_{25 \alpha}$ & $1.54 \times 10^{-9}$ & $3.24 \times 10^{-9}$ & 2.11 \\
\hline & $\beta_{25 \gamma}$ & -0.037 & 0.051 & -1.36 \\
\hline
\end{tabular}

methods used for both disease determination and field sampling. In this study, disease was inferred from the presence of granulomas in histologic sections of splenic tissue (Gauthier et al. 2008). Dermal mycobacteriosis was not rigorously 
Fig. 5. Estimated growth parameter effects from allometric model $\mathrm{M}_{\mathrm{al11}}$ for each level of the year-cruise covariate relative to the combined reference level (March 2003, disease status, and severity) for (a) the condition parameter $\alpha$ and $(b)$ slope parameter $\gamma$.
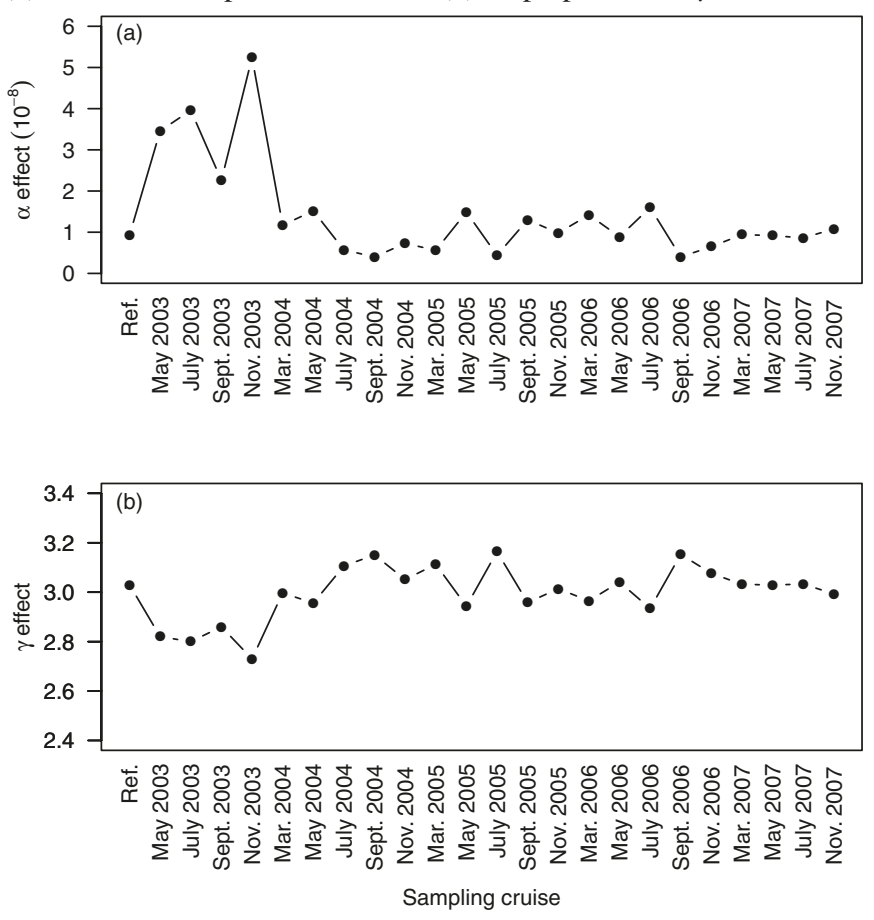

investigated but noted in fish when external lesions were macroscopically visible. The relationship between internal and external disease processes in striped bass is not fully understood at present, and it is possible that the presence and severity of the two conditions are not always similar in the same fish. Separate from the ChesMMAP survey, striped bass are also routinely sampled in the Rappahannock River, Virginia (a tributary of Chesapeake Bay), for intensive disease monitoring and evaluation. Data from this program indicate that dermal disease is highly predictive of splenic granulomas $(>90 \%)$ but that only a subset of fish with internal disease also possess dermal lesions (W.K. Vogelbein, Virginia Institute of Marine Science, unpublished data). Because our histological detection technique is based on examination of a subsample of splenic tissue, it is possible that some positive animals are misclassified as negative; however, this should be limited almost entirely to cases of very mild disease. As an alternative to histology, polymerase chain reaction (PCR) can be used to determine disease status. An obvious advantage of PCR is its ability to confirm infection; however, this approach does not provide any information on the viability of the organisms detected because it reacts to the presence of mycobacterial DNA. Moreover, it is possible to have a genuine positive result via histology and a corresponding negative PCR reaction due to the highly localized distribution of mycobacteria within splenic tissue.

Use of histologic granuloma detection can lead to an overestimation of apparent prevalence because of imperfect specificity due to the occasional presence of other granulomaeliciting agents such as trematode metacercariae. However, overestimation of apparent prevalence would weaken the sig- nificance of the disease status covariate in our growth analyses only if fish of sizes above and (or) below the size range of confirmed disease-negative fish were systematically misclassified as disease-positive. To our knowledge, the probability of a false-positive identification via histologic detection of splenic granulomas in striped bass is not related to fish age or size. It is also possible that disease status may affect the selectivity-at-age of striped bass sampled by the ChesMMAP trawl. Driving the estimated negative effects of the disease status covariate on the asymptotic sizes is the fact that the observed size-at-age of disease-positive fish is generally lower than that of disease-negative fish, particularly at older ages. For this disease pattern in size-at-age not to be present in the population and due to gear selectivity, the ChesMMAP trawl would have to select for larger diseasenegative and smaller disease-positive fish at a given age. Mycobacteriosis typically debilitates affected fishes (Nigrelli and Vogel 1963; Snieszko 1978; Bruno et al. 1998), so the probable trend is for disease-positive fish to have a higher relative selectivity-at-age than disease-negative fish. In this case, the trend in differential selectivity-at-age would certainly lead to an overestimation of apparent prevalence, but it would not affect the conclusion about slower growth by disease-positive fish.

In our analysis of striped bass growth data, we paid careful attention to characteristics of the observed data and graphically evaluated model fit and error structure (Quinn and Deriso 1999; Zuur et al. 2010). Although the symptoms of multiplicative error for the eviscerated mass-at-length and mass-at-age analyses were fairly obvious, the underlying error structure of the length-at-age data was less clear. The $Q Q$ plots of normality for the data on original and log scales both seemed reasonable, but plots of residuals as a function of age assuming additive error clearly showed patterns of increasing variance of length with age. Heterogeneity of variance does not generally affect the estimated $\beta_{j}$ s but it can lead to misleading estimates of precision (Carroll and Ruppert 1988), which would complicate inferences drawn regarding the significance of covariates. Although explicitly modeling the variance of the length observations with age might be preferred to weighted least squares when accounting for heteroscedasticity, analysis attempts that considered power-of-the-mean and related variance models led to numerical instability for several model parameterizations. We acknowledge that our application of weighted least squares relies heavily on the assumption that the sample variances of the lengths-at-age are reasonable estimates of the true variances and that this assumption may be questionable due to low observed sample size for some age classes. Some form of variance modeling was necessary, however, and inverse variance weighting was the most viable approach permitted by the data.

Few studies exist that document the effects of a chronic disease on the growth dynamics of wild finfish populations. One study examined the effect of presumptive mycobacteriosis on wild Atlantic mackerel (Scomber scombrus) and demonstrated some statistically significant reduction in growth for some groups of infected fish (MacKenzie 1988). Our ability to address questions about the impacts of mycobacteriosis on the growth of striped bass was possible because of a fairly extensive underlying data set. However, it should be noted that the sampling protocols of ChesMMAP were not origi- 
Table 5. Residual sum-of-squares (RSS), Akaike's information criterion (AIC), and $\triangle \mathrm{AIC}$ for models $\mathrm{M}_{\mathrm{vB}-\mathrm{all}}$, $\mathrm{M}_{\mathrm{vB}-\mathrm{al} 2}, \mathrm{M}_{\mathrm{vB}-\mathrm{al} 3}, \mathrm{M}_{\mathrm{vB}-\mathrm{al} 4}$, and $\mathrm{M}_{\mathrm{vB}-\mathrm{al5}}$ fitted to striped bass (Morone saxatilis) eviscerated mass-at-age data collected in the mainstem of Chesapeake Bay.

\begin{tabular}{lllllr}
\hline & & \multicolumn{2}{c}{ No. of } \\
Model & Covariates & RSS & parameters & AIC & \multicolumn{1}{c}{$\Delta$ AIC } \\
\hline $\mathrm{M}_{\mathrm{vB}-\mathrm{al} 1}$ & None & 580.7 & 4 & 3357.3 & 184.8 \\
$\mathrm{M}_{\mathrm{vB}-\mathrm{a} 2}$ & Sex & 555.6 & 7 & 3262.6 & 90.1 \\
$\mathrm{M}_{\mathrm{vB}-\mathrm{al} 3}$ & Disease status & 545.7 & 7 & 3221.9 & 49.4 \\
$\mathrm{M}_{\mathrm{vB}-\mathrm{al} 4}$ & Disease status, sex & 532.6 & 10 & 3172.5 & 0.0 \\
$\mathrm{M}_{\mathrm{vB}-\mathrm{al} 5}$ & Disease status, sex, severity & 539.8 & 13 & 3209.2 & 36.7 \\
\hline
\end{tabular}

Table 6. Parameter estimates, standard errors (SE), and coefficients of variation (CV) from model $\mathrm{M}_{\mathrm{al}-\mathrm{vB} 4}$ fitted to eviscerated mass-at-age data from striped bass (Morone saxatilis) collected in the mainstem of Chesapeake Bay (striped bass that were male and disease-negative were the reference levels of the covariates).

\begin{tabular}{llllr}
\hline Type & Parameter & Estimate & SE & CV \\
\hline Constant & $\beta_{0 w_{\infty}}$ & 7.67 & 1.67 & 0.22 \\
& $\beta_{0 k}$ & 0.11 & 0.013 & 0.12 \\
& $\beta_{0 t_{0}}$ & -1.64 & 0.16 & -0.10 \\
Sex & $\beta_{1 w_{\infty}}$ & 75.73 & 20.59 & 0.27 \\
& $\beta_{1 k}$ & -0.066 & 0.014 & -0.21 \\
& $\beta_{1 t_{0}}$ & -0.12 & 0.20 & -1.67 \\
Disease status & $\beta_{2 w_{\infty}}$ & -1.25 & 0.52 & -0.42 \\
& $\beta_{2 k}$ & -0.0048 & 0.0013 & -0.27 \\
& $\beta_{2 t_{0}}$ & -0.91 & 0.17 & -0.19 \\
\hline
\end{tabular}

Note: The value of $\gamma$ for model $\mathrm{M}_{\mathrm{vB}-\mathrm{al} 4}$ was fixed at 3.031.

nally developed to include disease monitoring. The core design of the survey outlined the collection of biological and ecological data in support of typical fisheries stock assessments. It was recognized early on though that the survey represented an ideal sampling platform to investigate populationlevel disease effects and that these types of questions were not being investigated for striped bass in Chesapeake Bay because of a lack of representative disease data. Although Chesapeake Bay is an important estuary that supports the production of many mid-Atlantic fishes, it is clearly not the only ecosystem worldwide that is impaired by eutrophication and other anthropogenic stressors (Diaz and Rosenberg 2008). Also, because it is well documented that anthropogenic stressors affect the physiological function of fish and may contribute to infectious diseases (Snieszko 1974; Sunyer et al. 1995; Blazer et al. 2010), it is reasonable to expect that infectious agents will persist within coastal ecosystems over the foreseeable future. Systematic population-level data will therefore be needed to document impacts on host populations, and we recommend that disease monitoring become a routine part of fish surveys or other appropriate coastal monitoring programs whenever possible.

An important question underlying the evaluation of mycobacteriosis on striped bass growth requires identifying whether fish maintain a normal or anticipated growth trajectory prior to infection that is then altered due to disease, or if fish destined to grow more slowly have an increased susceptibility to disease. The chronic nature and protracted disease course of mycobacteriosis suggests that the former interpretation may be most plausible. However, formal investigation of
Fig. 6. Observed eviscerated mass-at-age and predicted von Bertalanffy - allometric model growth curves derived from parameter estimates associated with model $\mathrm{M}_{\mathrm{vB}-\mathrm{al} 4}(a)$ female and $(b)$ male striped bass (Morone saxatilis) collected by the ChesMMAP survey during 2003-2007. In both panels, solid circles and the solid line correspond to disease-negative fish, and shaded circles and the shaded line represent disease-positive fish. Plots of predicted eviscerated mass-at-age were bias corrected for transformation from log space (standard error of the estimate, SEE $=0.485$; Sprugel 1983). For model $\mathrm{M}_{\mathrm{vB}-\mathrm{al} 4}, \gamma$ was fixed at 3.031.
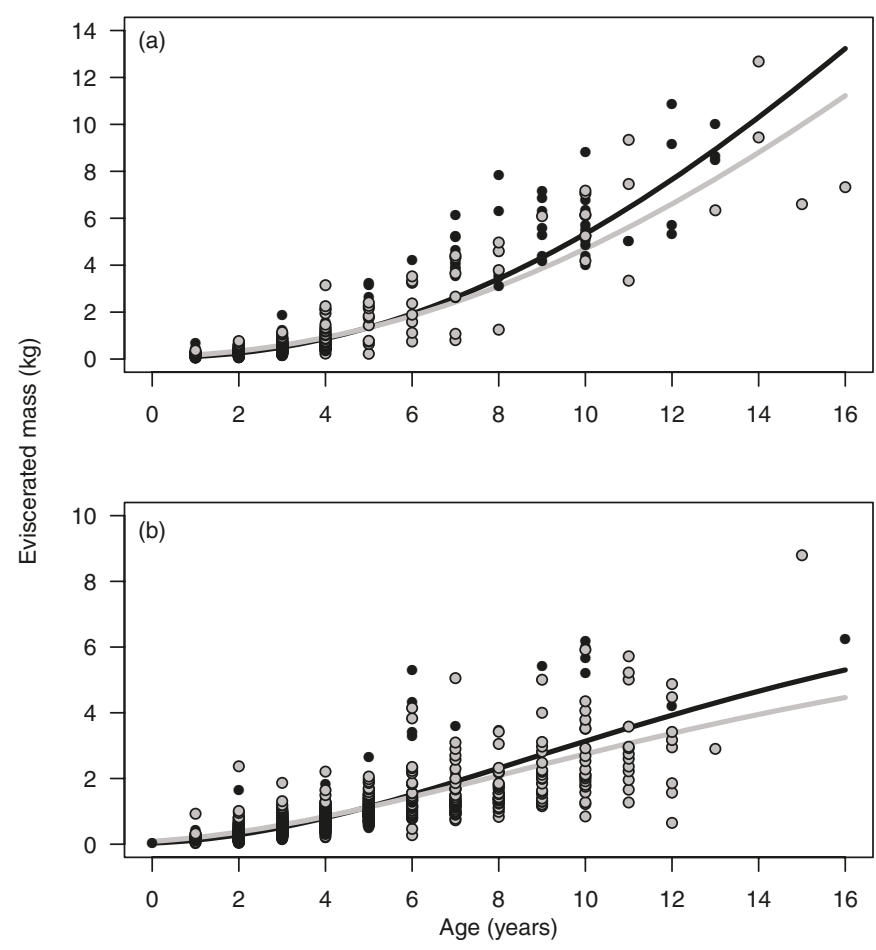

this question requires knowledge of the infection duration, which is not possible given the sampling approach underlying our data. Although this study has documented different growth trajectories for disease-positive and -negative fish, it is also important to recognize that several chronic infectious or inflammatory conditions other than mycobacteriosis may result in reduced growth. Gross abnormalities such as spinal defects and wounds could lead to restricted growth and poor condition, but these are rarely observed in striped bass collected in Chesapeake Bay by the ChesMMAP platform. Although encysted trematodes have been documented in striped bass from the bay, severe infections with these agents were rarely noted in the specimens collected for this study. 
We do acknowledge that a supravening condition not visible by gross examination or spleen histology could be present in Chesapeake Bay striped bass; however, such a condition would need to be correlated with mycobacteriosis as measured by our methods to adversely affect the results of our study. At the present time, we know of no other such condition.

Spatial variation in the apparent prevalence, disease severity, and impacts on growth was not investigated in this study because of concerns about confounding due to seasonal movements of striped bass within segments of the bay between sampling events. Estimates of total coastwide striped bass abundance and female spawning stock biomass (SSB) are currently high, with female SSB at $185 \%$ of the threshold reference point and $148 \%$ of the target reference point (Atlantic States Marine Fisheries Commission 2009). This high abundance has motivated speculation that striped bass may be near carrying capacity; however, all fish (disease-positive and -negative) would be expected to experience the effects of crowding and thus any associated loss of condition if disease has no effect. As mycobacteriosis is associated with stressful conditions in aquaculture, overcrowding stress in the wild could certainly be a contributing factor to the high apparent prevalence.

Scientific advancements often generate additional research questions, and this study poses no exception to that general rule. Evidence that mycobacteriosis negatively affects striped bass growth is an important result, yet it almost immediately leads to a host of new research questions. Physiology, behavior, trophic ecology, and overall fitness all underlie the growth process, so understanding disease impacts on these topics constitute natural next steps. If we turn our attention to the direct implications of lower striped bass productivity through reduced growth, an immediate concern for fisheries managers is loss of fishery biomass yields. Further, because egg productivity is often a function of size in fishes, with the larger females generally contributing more total eggs per spawning season, the lower estimated asymptotic sizes documented in this study would suggest that the egg productivity of disease-positive fish would be less than that of diseasenegative fish. Although mycobacteriosis in striped bass is observed predominately in Chesapeake Bay fish, the bay population can contribute up to $90 \%$ of the Atlantic coastal landings (Van Winkle et al. 1988; Richards and Rago 1999), which implies that impacts of mycobacteriosis have the potential to affect geographical areas well beyond Chesapeake Bay.

\section{Acknowledgements}

The authors acknowledge R. Johnson, E. Brasseur, D. Parthree, M. Chattin, W. Lange, E. McOmber, J. Gregg, K. Spanik, and A. Boddicker for their efforts associated with field collections and sample processing and thank Captains L.D. Ward and J. Olney, Jr., for their contributions to vessel operations. Funding was provided by the NOAA Chesapeake Bay Office, the Virginia Environmental Endowment, the U.S. Fish and Wildlife Service, the Virginia Marine Resources Commission, and the Plumeri Award for Faculty Excellence at the College of William \& Mary. This is VIMS contribution 3186 .

\section{References}

Akaike, H. 1973. Information theory as an extension of the maximum likelihood principle. In Second International Symposium on Information Theory. Edited by B.N. Petrov and F. Csaki. Akademiai Kiado, Budapest, Hungary. pp. 267-281.

Atlantic States Marine Fisheries Commission. 2009. The 2009 stock assessment report for Atlantic striped bass. Atlantic States Marine Fisheries Commission (ASMFC), Washington, D.C.

Beck, M.W., Heck, K.L., Jr., Able, K.W., Childers, D.L., Eggleston, D.B., Gillanders, B.M., Halpern, B., Hays, C.G., Hoshino, K., Minello, T.J., Orth, R.J., Sheridan, P.F., and Weinstein, M.P. 2001. The identification, conservation, and management of estuarine and marine nurseries for fish and invertebrates. Bioscience, 51(8): 633-641. doi:10.1641/0006-3568(2001)051[0633:TICAMO]2.0. $\mathrm{CO} ; 2$.

Blazer, V.S., Iwanowicz, L.R., Starliper, C.E., Iwanowicz, D.D., Barbash, P., Hedrick, J.D., Reeser, S.J., Mullican, J.E., Zaugg, S.D., Burkhardt, M.R., and Kelble, J. 2010. Mortality of centrarchid fishes in the Potomac Drainage: survey results and overview of potential contributing factors. J. Aquat. Anim. Health, 22(3): 190-218. doi:10.1577/H10-002.1. PMID: 21192549.

Brandt, S.B., and Kirsch, J. 1993. Spatially explicit models of striped bass growth potential in Chesapeake Bay. Trans. Am. Fish. Soc. 122(5): 845-869. doi:10.1577/1548-8659(1993)122<0845: SEMOSB $>2.3 . \mathrm{CO} ; 2$.

Bruno, D.W., Griffiths, J., Mitchell, C.G., Wood, B.P., Fletcher, Z.J., Drobniewski, F.A., and Hastings, T.S. 1998. Pathology attributed to Mycobacterium chelonae infection among farmed and laboratory-infected Atlantic salmon Salmo salar. Dis. Aquat. Organ. 33(2): 101-109. doi:10.3354/dao033101. PMID:9684316.

Burnham, K.P., and Anderson, D.R. 2002. Model selection and multimodel inference: a practical information-theoretic approach. 2nd ed. Springer-Verlag, New York.

Carroll, R.J., and Ruppert, D. 1988. Transformations and weighting in regression. Chapman \& Hall, New York.

Clarke, G.L. 1946. Dynamics of production in a marine area. Ecol. Monogr. 16(4): 321-335. doi:10.2307/1961639.

Collette, B.B., and Klein-MacPhee, G. 2002. Fishes of the Gulf of Maine. 3rd ed. Smithsonian Institution Press, Washington, D.C.

Davidian, M., and Giltinan, D.M. 1995. Nonlinear models for repeated measurement data. Chapman and Hall, New York.

-Diaz, R.J., and Rosenberg, R. 2008. Spreading dead zones and consequences for marine ecosystems. Science, 321(5891): 926929. doi:10.1126/science.1156401. PMID:18703733.

-Dorazio, R.M., Hattala, K.A., McCollough, C.B., and Skjeveland, J.E. 1994. Tag recovery estimates of migration of striped bass from spawning areas of the Chesapeake Bay. Trans. Am. Fish. Soc. 123(6): 950-963. doi:10.1577/1548-8659(1994)123<0950: TREOMO $>2.3 . \mathrm{CO} ; 2$.

Gauthier, D.T., and Rhodes, M.W. 2009. Mycobacteriosis in fishes: a review. Vet. J. 180(1): 33-47. doi:10.1016/j.tvj1.2008.05.012. PMID:18620877.

Gauthier, D.T., Latour, R.J., Heisey, D.M., Bonzek, C.F., Gartland, J., Burge, E.J., and Vogelbein, W.K. 2008. Mycobacteriosis-associated mortality in wild striped bass (Morone saxatilis) from Chesapeake Bay, USA. Ecol. Appl. 18(7): 1718-1727. doi:10. 1890/07-2083.1. PMID:18839766.

Greenstreet, S.P.R., and Rogers, S.I. 2006. Indicators of the health of the North Sea fish community: identifying reference levels for an ecosystem approach to management. ICES J. Mar. Sci. 63(4): 573593. doi:10.1016/j.icesjms.2005.12.009.

Houde, E.D. 1987. Fish early life dynamics and recruitment variability. Am. Fish. Soc. Symp. 2: 17-29. 
Jiang, H., Pollock, K.H., Brownie, C., Hoenig, J.M., Latour, R.J., Wells, B.K., and Hightower, J.E. 2007. Tag return models allowing for harvest and catch and release: evidence of environmental and management impacts on striped bass fishing and natural mortality rates. N. Am. J. Fish. Manage. 27(2): 387-396. doi:10.1577/M06-089.1.

Kemp, W.M., Boynton, W.R., Adolf, J.E., Boesch, D.F., Boicourt, W.C., Brush, G., Cornwell, J.C., Fisher, T.R., Glibert, P.M., Hagy, J.D., Harding, L.W., Houde, E.D., Kimmel, D.G., Miller, W.D., Newell, R.I.E., Roman, M.R., Smith, E.M., and Stevenson, J.C. 2005. Eutrophication of Chesapeake Bay: historical trends and ecological interactions. Mar. Ecol. Prog. Ser. 303: 1-29. doi:10.3354/meps303001.

-Kimura, D.K. 2008. Extending the von Bertalanffy growth model using explanatory variables. Can. J. Fish. Aquat. Sci. 65(9): 18791891. doi:10.1139/F08-091.

Kohlenstein, L.C. 1981. On the proportion of the Chesapeake Bay stock of striped bass that migrates into the coastal fishery. Trans. Am. Fish. Soc. 110(1): 168-179. doi:10.1577/1548-8659(1981) $110<168$ :OTPOTC $>2.0 . C O ; 2$.

-MacKenzie, K. 1988. Presumptive mycobacteriosis in North-east Atlantic mackerel, Scomber scombrus L. J. Fish Biol. 32(2): 263275. doi:10.1111/j.1095-8649.1988.tb05360.x.

-Mertz, G., and Myers, R.A. 1998. A simplified formulation for fish production. Can. J. Fish. Aquat. Sci. 55(2): 478-484. doi:10.1139/ f97-216.

Murdy, E.O., Birdsong, R., and Musick, J.A. 1997. Fishes of Chesapeake Bay. Smithsonian Institute Press, Washington, D.C.

Nigrelli, R.F., and Vogel, H. 1963. Spontaneous tuberculosis in fishes and in other cold-blooded vertebrates with special reference to Mycobacterium fortuitum Cruz from fish and human lesions. Zoologica (N.Y.) 48: 131-144.

Overton, A.S., Margraf, F.J., Weedon, C.A., Pieper, L.H., and May, E.B. 2003. The prevalence of mycobacterial infections in striped bass in Chesapeake Bay. Fish. Manag. Ecol. 10(5): 301-308. doi:10.1046/j.1365-2400.2003.00364.x.

Quinn, T.J., and Deriso, R.B. 1999. Quantitative fish dynamics. Oxford University Press, New York.

R Development Core Team. 2010. R: a language and environment for statistical computing. R Foundation for Statistical Computing, Vienna, Austria.

- Rhodes, M.W., Kator, H., Kotob, S., van Berkum, P., Kaattari, I., Vogelbein, W.K., Quinn, F., Floyd, M.M., Butler, W.R., and Ottinger, C.A. 2003. Mycobacterium shottsii sp. nov., a slowly growing species isolated from Chesapeake Bay striped bass (Morone saxatilis). Int. J. Syst. Evol. Microbiol. 53(2): 421-424. doi:10.1099/ijs.0.02299-0. PMID:12710607.

-Rhodes, M.W., Kator, H., Kaattari, I., Gauthier, D.T., Vogelbein, W.K., and Ottinger, C.A. 2004. Isolation and characterization of mycobacteria from striped bass Morone saxatilis from the Chesapeake Bay. Dis. Aquat. Organ. 61(1-2): 41-51. doi:10. 3354/dao061041. PMID:15584409.
Rhodes, M.W., Kator, H., McNabb, A., Deshayes, C., Reyrat, J., Brown-Elliott, B.A., Wallace, R., Jr., Trott, K.A., Parker, J.M., Lifland, B., Osterhout, G., Kaattari, I., Reece, K., Vogelbein, W.K., and Ottinger, C.A. 2005. Mycobacterium pseudoshottsii sp. nov., a slowly growing chromogenic species isolated from Chesapeake Bay striped bass (Morone saxatilis). Int. J. Syst. Evol. Microbiol. 55(3): 1139-1147. doi:10.1099/ijs.0.63343-0. PMID:15879246.

-Richards, R.A., and Rago, P.J. 1999. A case history of effective fishery management: Chesapeake Bay striped bass. N. Am. J. Fish. Manage. 19(2): 356-375. doi:10.1577/1548-8675(1999) $019<0356$ :ACHOEF>2.0.CO;2.

Setzler, E.M., Boynton, W.R., Wood, K.V., Zion, H.H., Lubbers, L., Mountford, N.K., Frere, P., Tucker, L., and Mihursky, J.A. 1980. Synopsis of biological data on striped bass, Morone saxatilis (Walbaum). NOAA (National Oceanic and Atmospheric Administration) Technical Report NMFS (National Marine Fisheries Service) Circular 433, Silver Spring, Maryland.

-Snieszko, S.F. 1974. The effects of environmental stress on the outbreaks of infectious diseases of fishes. J. Fish Biol. 6(2): 197208. doi:10.1111/j.1095-8649.1974.tb04537.x.

Snieszko, S.F. 1978. Mycobacteriosis (tuberculosis) of fishes. U.S. Fish Wildl. Fish Dis. Leaflet 55.

-Sprugel, D.G. 1983. Correcting for bias in log-transformed allometric equations. Ecology, 64(1): 209-210. doi:10.2307/1937343.

-Sunyer, J.O., Gómez, E., Navarro, V., Quesada, J., and Tort, L. 1995. Physiological responses and depression of humoral components of the immune system in gilthead seabream (Sparus aurata) following daily acute stress. Can. J. Fish. Aquat. Sci. 52(11): 2339-2346. doi:10.1139/f95-826.

Van Winkle, W., Kumar, K.D., and Vaughan, D.S. 1988. Relative contributions of the Hudson River and Chesapeake Bay striped bass stocks to the Atlantic coastal population. In Science, law, and Hudson River power plants: a case study in environmental impact assessment. Edited by L.W. Barnthouse, R.J. Klauda, D.S. Vaughan, and R.L. Kendall. Am. Fish. Soc. Monogr. 4, Bethesda, Maryland. pp. 255-266.

Vogelbein, W.K., Zwerner, D.E., Kator, H., Rhodes, M.W., and Cardinal, J. 1999. Mycobacteriosis of striped bass from Chesapeake Bay. Virginia Institute of Marine Science, Gloucester Point, Virginia, VIMS Special Scientific Report 139.

von Bertalanffy, L. 1938. A quantitative theory of organic growth. Hum. Biol. 10: 181-213.

Zastrow, C.E., Houde, E.D., and Saunders, E.H. 1989. Quality of striped bass (Morone saxatilis) eggs in relation to river source and female weight. Rapp. P.-V. Reun. Cons. Int. Explor. Mer, 191: 3442.

Zuur, A.F., Leno, E.N., and Elphick, C.S. 2010. A protocol for data exploration to avoid common statistical problems. Methods Ecol. Evol. 1: 3-14. 